\title{
Research on Mechanism of Active Oil Controlling Water and Enhanced Oil Production
}

\author{
YUAN Jingshu' ${ }^{1}$, ${ }^{\text {, LI Yiqiang }}{ }^{1}$, YAO Guijie ${ }^{2}$ XU Yang ${ }^{3}$, LI Yao ${ }^{3}$, ZHANG \\ Pengyi ${ }^{1}$ \\ ${ }^{1}$ Enhanced Oil Recovering research center, China University of Petroleum(Beijing), Changping, \\ Beijing 102249, China \\ ${ }^{2}$ PetroChina Dagang Petrochemical Company, Dagang Oil Field, Tianjin, 300280,China \\ ${ }^{3}$ School of Petroleum Engineering , China University of Petroleum(Beijing), Changping , \\ Beijing 102249 , China \\ a18811139711@163.com
}

Key words: active oil; emulsion; selectivity; plugging agent; mechanism ;enhancing oil production.

Abstract. Active crude oil water plugging is a kind of water plugging technology without damage to the reservoir selectivity, and can achieve a good water plugging and enhancing oil production of purpose. Aiming at some problems existing in water blocking activity of crude oil research, research and solve some of the following issues: First, experimental study on the matching relationship between crude oil component and emulsifier, the activie crude oil and water plugging, selective plugging big channels for water effectively, the HLB value of 3.5 6.0 surfactant as emulsifier is better. Second, on the active crude adaptive control water and increase oil micro mechanism of active oil into the oil: crude oil in high water cut channel, in the fine pore throat due to shear the emulsion is formed, the formation of Jiamin action, the flow channel was blocked up with emulsified oil, water flow around the jam, into the oil flow channel, play the good water plugging and oil increase effect. In addition, the effects of ion composition, viscosity and sealing strength of petrophysical parameters on emulsion formation water influence viscosity and sealing strength of emulsion and injection time of water plugging effect is studied and the corresponding conclusion is drawn. These important conclusions through research have important guiding significance for the development of water flooding oilfield.

\section{Introduction}

For Water flooding development oilfield, it is a common problem for breakthrough oil well. Because the breakthrough oil well will be consumed formation energy, it will effect EOR of crude oil. The problem of breakthrough oil well will be further intensified, after oil field development enters middle-late stages. Since most of the water from the injection well injection water along the water flow in the reservoir macroscopic throats from oil well production quickly, these injection water does not play a role driving oil, which results in water resource. That is, low efficiency or invalid circulation, resulting in waste of water resources. At the same time, a large increase in the amount of the production of liquid dehydration, the cost of crude oil production increased. In order to reduce oil production, the most direct way is water plugging. Oil well water plugging is an important measure to maintain the normal production of oil well, especially in the medium and high water cut period. Water plugging is an important measure to increase the water spread coefficient and increase the oil recovery. Because of the high selectivity and no pollution to the oil flow channel, the water plugging technology of active crude oil has attracted people 's interest, and has been applied in some zone of oil fields. After application, it is found that when oil field development is in low water cut, it is better to control water and increase oil recovery. With the development of oil field, the water cut of oil wells is gradually increasing, and problem of 
breakthrough oil well will become more prominent. However, the implementation of active crude oil process measures to increase the amount of single well oil increased gradually declined, the cost of a single well oil increased year by year.Therefore, it is necessary to study the geological and development characteristics of the high water cut stage in the oil field, and to observe the emulsifying property and the distribution of the active crude oil and its effect on the channel. In order to study effect of water plugging on increased oil, these issues must be studied, such as properties of oil and formation water, type of emulsifier and additives, and concentration, residual oil distribution, reservoir physical properties, injection parameters and so on. Aimed to find out the relationship between the different factors and the effect of measures, and to determine the mechanism of active crude oil controlling water and increased oil, and to determine the adjustment principle and the optimum dosage of the chemical composition of the single well.

\section{Overview of related research}

More than $80 \%$ of onshore oil and the gas field in China is developed by water injection, with the oil and gas field developed in the late stage, most oil and gas fields have been flooded. These water from breakthrough oil well will lead to the formation energy consumption, lower recovery of crude oil, pipeline, corrosion and scaling intensifies, if these water is drained outside, which can also cause environmental pollution hazards. After the formation is determined yielding water, the mechanical or chemical method to plug the well inflow is employed to change the flow direction. Non selective water plugging not only plug water, but also crude oil, namely, no selectivity. Selective water plugging is mainly to employ the difference between the oil and water and the nature of the oil layer and water, which can reach to plug water and not to plug oil [1,2],For not needing to explore water and not needing to pull the strings from oil well, the method can control water in deep formation, selective water plugging is becoming more and more popular in favor of oilfield[3].

\section{The related work of selective water plugging}

Selective water plugging agent has the nature plugging water and not plugging oil, when it enters the target formation, can plug about $80 \%$ formation water, nevertheless, plug oil less than $30 \%$ crude oil, therefore, it is especially suitable for those oil wells where crude oil and water locate in the same as formation of oil well[2]. The research of chemical water plugging technology began in 1950s, in china, after a long-term research and development of experimental and application, a lot of performance of the mature selective water shutoff agent [3] have been developed, which includes the types of polymer plugging agent, expansion type of blocking agent, type of crude oil plugging agent and foam type of blocking agent. For crude oil type of water plugging agent, it generally is made of high viscosity crude oil emulsifier, including active crude oil, coupled with crude oil and solid crude oil powder, etc., this type crude oil plugging agent is , is a kind of Recyclable use water plugging agent. The active crude oil is refer to join the oil in water (w / O) emulsifier, with certain viscosity of crude oil, the oil plugging effect is very small, residual resistance coefficient is only about 1.5 , and which is strong for water plugging, the residual resistance coefficient of maximum 8.3[4].The key to the effect of water plugging agent is that the composition of crude oil and the type of emulsifier, if gum and asphaltene in crude oil, is higher and the lower the tension of oil-water interfacial tension, it will become more emulsion[5,6]. These technologies are widely applied in the oil reservoir of Liaohe Oilfield[7,8].In recent years, It emerges much research on the active crude oil water plugging water agent, in domestic oil field. In order to improve the effect of active crude oil plugging, Xiang Yan-an[9] determined reasonable plugging radius again, through indoor physical simulation studied on optimization of construction technology, and pointed out that the use of a small amount of preflush and excess replacement fluid injection production process blocking water is better. The research of Qu Yuzhong shows that the surface of the rock is made by the surface coating technology, and the surface of the rock is wet by 
water, and the adsorption capacity of the crude oil is enhanced, and increasing the distance, can optimize the water plugging technology of active crude oil.

\section{The research of mechanism of selective water plugging agent}

There are many kinds of selective water plugging agents which have been developed and put into use in oilfield. The mechanism of water plugging in different selective water plugging agents is different. These mechanisms can be divided into 4,They are adsorption, trapping and physical mechanism, expansion and contraction, instability mechanism, mechanism of oil / water passage, respectively. The selective water plugging agent will give priority to enter the high water bearing layer, and through hydrogen bond or electrostatic attraction on the exposed surface, the molecules that do not be attracted can be stretched in the water, forming a space network structure which be able to form physical plugging. These blockage must reduce the relative permeability of water in the porous media[1]. Al-Sharji observed that some polymer is attracted and 1 accumulated on the surface of sandstone, when the polymer flows slowly, under the microscope and discovered that the polymer flow resistance increases obviously when the original formation water is replaced with the polymer, during injection pressure test.

\section{Effect of crude oil properties on the performance of active oil water Plugging agent}

\section{Analysis of crude oil physical properties}

Asphaltene usually refers to the oil insoluble in small molecule alkanes (such as n-pentane, positive such as heptane) and soluble in benzene substances, its molecular weight is the biggest , and polar is strongest and is non hydrocarbon component. Asphaltene is the main factor to form crude oil emulsion. This kind of natural emulsifier (W/O), which can form a tough elastic film at the oil-water interface, plays an important role in the stability of oil and water emulsion. Compared with the asphaltene, gum formation elastic membrane strength is weak, but the resin can interact with asphaltene, and when the two ratio is up to a certain value, emulsion becomes most stable, Therefore, different emulsifiers on the adaptability of different crude oil.In this experiment, the research object of active oil water plugging is produced in several blocks of Liaohe Oilfield and Daqing oilfield, and the physical property parameters are determined, the results are shown in Table 1.

Table 1. Parameters analysis of crude oil physical properties

\begin{tabular}{|l|l|l|l|l|l|}
\hline $\begin{array}{l}\text { Oil Sample } \\
\text { NO. }\end{array}$ & $\begin{array}{l}\text { Crude oil density } \\
(\mathrm{g} / \mathrm{cm} 3)\left(20^{\circ} \mathrm{C}\right)\end{array}$ & $\begin{array}{l}\text { Freezing } \\
\text { point }\left({ }^{\circ} \mathrm{C}\right)\end{array}$ & $\begin{array}{l}\text { Paraffin content } \\
(\%)\end{array}$ & $\begin{array}{l}\text { Asphalt content } \\
(\%)\end{array}$ & $\begin{array}{l}\text { Gum content } \\
(\%)\end{array}$ \\
\hline J16 & 0.9317 & 21 & 3.48 & 2.83 & 18.34 \\
\hline DQ1 & 0.9003 & 36 & 28.5 & 4.98 & 25.7 \\
\hline DQGD & 0.8615 & 30 & 19.7 & 0.98 & 15.9 \\
\hline DQAN & 0.8812 & 34 & 16.6 & 1.35 & 14.64 \\
\hline
\end{tabular}

\section{Viscosity temperature properties of crude oil}

In order to investigate the adaptability of LHJ-1 to crude oil, we chose three kinds of crude oil, in which the mixing intensity was 2000rpm, the concentration of emulsifier if LHJ-1 was 4\%, the water cut was $50 \%$, under the condition of $50 \%$ water cut, the emulsion is prepared. The three kinds of crude oil are: Daqing Gudong crude oil $\left(45^{\circ} \mathrm{C}\right.$ when the viscosity of crude oil is $\left.40 \mathrm{mPa} \cdot \mathrm{s}\right)$, Daqing Aonan oil $\left(45^{\circ} \mathrm{C}\right.$ when crude oil viscosity is $\left.325 \mathrm{mPa} \cdot \mathrm{s}\right)$, Daqing oil production plant 1 of crude oil $\left(45^{\circ} \mathrm{C}\right.$ when crude oil viscosity is $\left.1300 \mathrm{mPa} \cdot \mathrm{s}\right)$, the three kinds of crude oil at different temperatures, with temperature variation curves as shown in Figure 1 and Figure 2. 


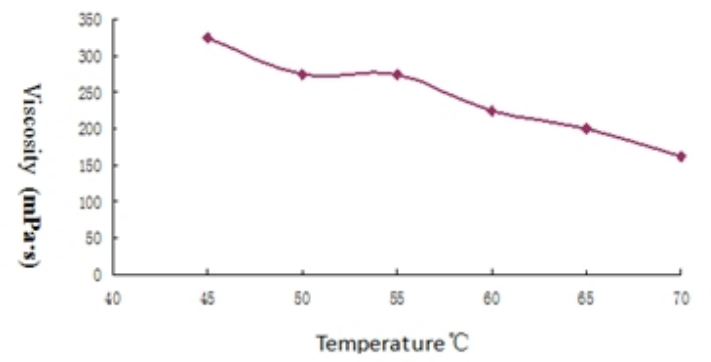

Figure 1. Viscosity and Temperature cuve for Aonan oilfield

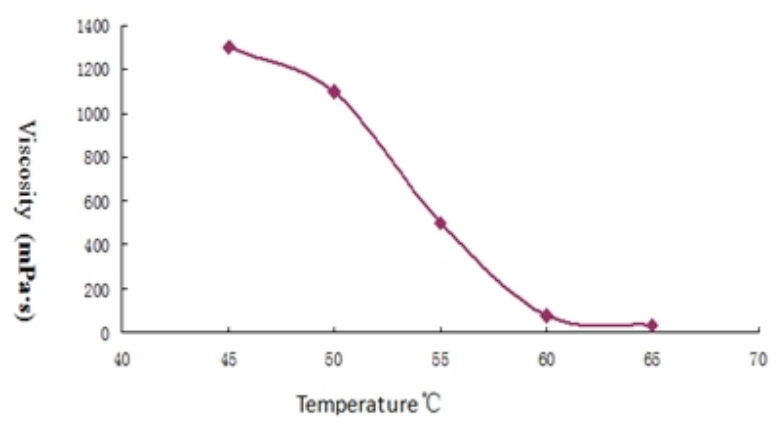

Figure 2. Viscosity and Temperature cuve for production plant 1

\section{Viscosity temperature properties of emulsion}

By means of rotational viscometer, Under different temperature, emulsion viscosity formed emulsifying agent can be determined, and which was compared with the viscosity of formed $4 \%$ LHJ-1 emulsion emulsified liquid to evaluate the emulsifying properties of composed emulsifier. Different emulsifiers being emulsified formed the emulsion viscosity changing with temperature varied with temperature is shown in figure 3. From figure 3, it can be seen that the Gudong oil and Daqing oil was formed in the water in oil emulsions, and, for external phase, the higher viscosity corresponding to the viscosity of the emulsion is higher.

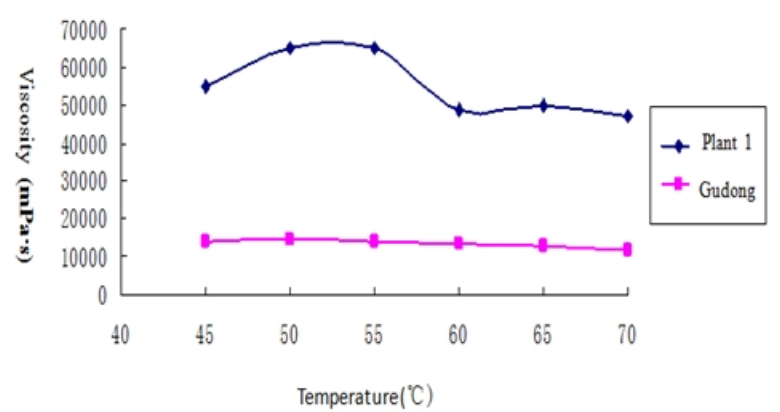

Figure 3. Viscosity and Temperature cuve for different crude oil emulsion formed

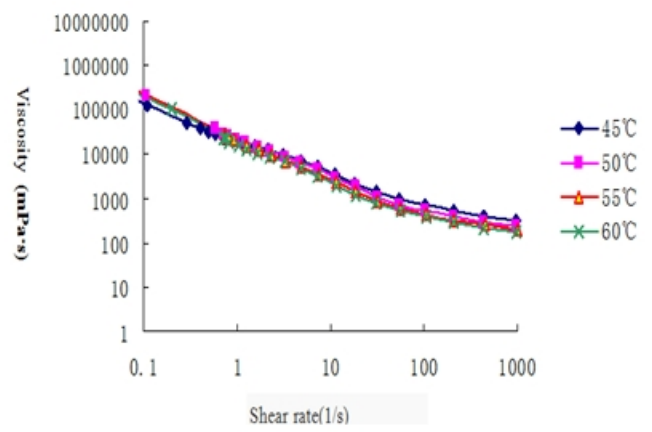

Figure 4. A Rheological curve comprison chart of crude oil emulsion of plant 1 at different temperatures

\section{Determination of rheological property of emulsion}

the shear rate of the emulsion and apparent viscosity of the emulsion formed by crude oil of plant 1 is measured, as shown in Figure 4, and the relationship between the shear rate and the apparent viscosity of the emulsion formed by the Gudong crude oil is shown in Figure 5; Figure 4 and figure 5 show that rheology curve of emulsion formed shows that water in oil emulsion is a non Newtonian fluid, it appears shear thinning characteristics. Due to the increase of the concentration, the distance between the dispersed phase droplets decreases, the interaction is enhanced, and in the Fan Dehua force and other factors, the droplets begin to aggregate into the cluster, and a certain amount of continuous phase is enveloped, which results in a decrease in the effective volume of the continuous phase and the

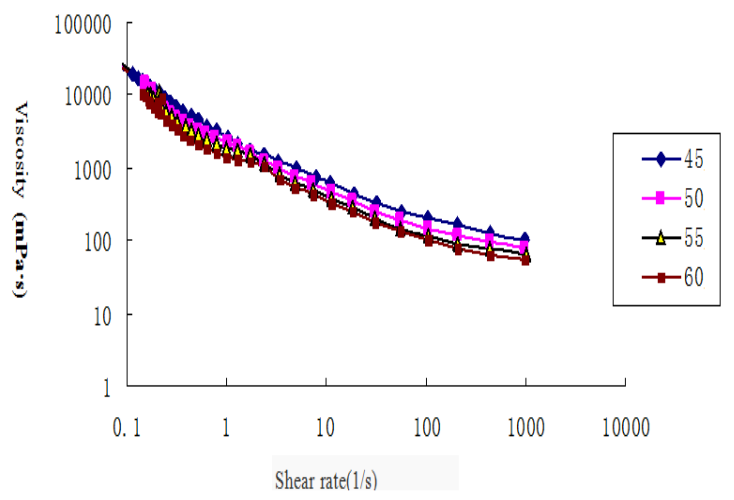

Figure 5. A Rheological curve comparison chart of crude oil emulsion of Gudong at different temperatures effective concentration of dispersed phase increased, the viscosity of emulsion is also increased. Under the shear condition, with the increase of shear rate, the cluster structure is gradually destroyed, the effective concentration of the dispersed phase is decreased, and the emulsion viscosity decreases, and appears shear thinning characteristics. With the further increase of the shear rate, the cluster structure is completely destroyed, and finally, The viscosity of the emulsion tends to be balanced. 


\section{Conclusions}

Through the research above, the conclusion is drawn as follows:

First, In order to achieve effective selective plugging large pore water, should choose the HLB value of $3.5 \sim 6$ surfactant as emulsifier, so as to form water in oil emulsion of crude oil, the crude oil which contains high content of resin and asphaltene and the high viscosity should match relationship with emulsifier better, and the crude oil emulsified viscosity should become large.

Second, active oil is mixed with the residual oil after entering the oil channel, forming a continuous oil phase, after entering channel of high water cut, the active crude oil should form the emulsion at the small throat, because of shear action. Because of the Jiamin action, after emulsification ,the formation of oil in the water oil beads should plug near throat around flow channels, thereby, these methods have played a good role in plugging water and increasing oil.

Third, with the increase of permeability, the ultimate recovery of the oil is small, which indicates that the water plugging technology of the emulsified oil is better for the low permeability reservoir.

Fourth, the salinity should be controlled in a relatively moderate range, experimental data shows that the salinity of $3000 \mathrm{mg} / \mathrm{L}$ is the best value.

Finally, different water cut has certain influence on the water plugging effect of emulsified oil, with the increase of water cut, crude oil recovery increases first, when it reaches a maximum value, later, it begins to decline.

\section{Acknowledgements}

This work was financially supported by the National Natural Science Foundation of China(51374221).The authors also appreciate CAO Guangsheng professor of Northeast Petroleum University. The corresponding author is YUAN Jingshu, the mail: 18811139711@163.com.

\section{References}

[1] ZHAO Fu-lin.Oilfield Chemistry[M].Shan dong dong ying:China University of Petroleum press,2007:148.

[2] LIU Yi-Jiang,WANG Xiang-Zeng. Chemical profile control and water plugging technology[M]. Beijing Petroleum Industry Press, 1999:185.

[3] YANG Yan,WANG Ye-Fei,ZHANG Peng, The mechanism and application of influencing factors of selecting whipped water plugging agent $[\mathrm{J}]$, Oilfield Chemistry[J]. Oilfield Chemistry, 2012,29(4):502-50

[4[ GAO Yu-Jun,MA Chun-Bao,FU Kui-Shi. High selective water shutoff technology for heavy oil[J]. Oilfield Chemistry, 1997, 14( 3) : 224 - 229.

[5] WANG Gui-Xun,CHAI De-Ming,ZHANG Qing-Hua.Study on selective water shutoff of crude oil[J]. Drilling technology, $2005,28(1): 86-88$.

[6] ZHAO Fu-Lin. Oil production with agent[M]. Shan dong dong ying: University of petroleum press, 2001:70.

[7] BAI Bao-Jun.HAN Ming,GAO Yu-Jun. Activated water plugging technology research and application of heavy oil[J]. Petroleum exploration and development,1998, 25(4): 81 - 83 .

[8] XIANG Yan-An. Kam 626 pieces of water control, the research and practice of stabilizing oil[J]. Inner Mongolia petrochemical industry , 2011 , 37( 7) : 216 - 217. 
[9] QU Yu-Zhong. Thickened oil water plugging technology application in reservoir north block jin 16 in the floor[J]. Inner Mongolia petrochemical industry , 2011, 37( 7) : 263 - 264. 